\title{
Innate Allorecognition and Memory in Transplantation
}

\author{
Daqiang Zhao ${ }^{1,2}$, Khodor I. Abou-Daya ${ }^{1}$, Hehua Dai ${ }^{1}$, Martin H. Oberbarnscheidt ${ }^{1,3,4}$, \\ Xian C. Li ${ }^{5}$ and Fadi G. Lakkis ${ }^{1,3,6 *}$ \\ ${ }^{1}$ Thomas E. Starzl Transplantation Institute, Department of Surgery, University of Pittsburgh, Pittsburgh, PA, United States, \\ ${ }^{2}$ Department of Urology, Union Hospital, Tongji Medical College, Huazhong University of Science and Technology, Wuhan, \\ China, ${ }^{3}$ Department of Immunology, University of Pittsburgh, Pittsburgh, PA, United States, ${ }^{4}$ Department of Critical Care \\ Medicine, Center for Critical Care Nephrology, University of Pittsburgh, Pittsburgh, PA, United States, ${ }^{5}$ Immunobiology \& \\ Transplant Science Center and Department of Surgery, Houston Methodist Hospital, Texas Medical Center, Houston, TX, \\ United States, ${ }^{6}$ Department of Medicine, Renal-Electrolyte Division, University of Pittsburgh, Pittsburgh, PA, United States
}

Over the past few decades, we have witnessed a decline in the rates of acute rejection without significant improvement in chronic rejection. Current treatment strategies principally target the adaptive immune response and not the innate response. Therefore, better understanding of innate immunity in transplantation and how to target it is highly desirable. Here, we review the latest advances in innate immunity in transplantation focusing on the roles and mechanisms of innate allorecognition and memory in myeloid cells. These novel concepts could explain why alloimmune response do not abate over time and shed light on new molecular pathways that can be interrupted to prevent or treat chronic rejection.

Keywords: allorecognition, innate immunity, transplantation, monocyte, dendritic cell

Activation of the innate immune system is necessary for driving adaptive immune responses $(1,2)$. In infection, pathogen-associated, non-self, molecules trigger host innate defenses and induce maturation of antigen-presenting cells (APCs) by binding to germline-encoded pattern recognition receptors [e.g., Toll-like receptors (TLRs)]. Mature APCs then initiate and sustain adaptive immunity by presenting antigen and providing co-stimulation to $\mathrm{T}$ cells.

How transplanted organs (allografts) induce APC maturation is less clear. Initial, landmark experiments suggested a role for TLRs by demonstrating that deletion of Myd88 downstream of TLRs blocks dendritic cell (DC) maturation and prevents rejection of single minor histocompatibility antigen-mismatched grafts (3). Later studies however showed that the rejection of MHC- or multiple minor antigen-mismatched allografts can still proceed in the absence of TLR signaling $(4,5)$. Moreover, deletion of additional microbial sensing pathways failed to completely prevent rejection (6-8). Similarly, the alternate hypothesis that "danger" molecules released at time of transplantation due to tissue injury trigger APC maturation could not account for alloimmune responses initiated after injury has subsided $(9,10)$. For example, allografts parked for a long time in T cell-deficient hosts were promptly rejected when $\mathrm{T}$ cells were replenished despite absence of discernible inflammation or injury in the graft at the time of $\mathrm{T}$ cell transfer (11-15). These observations raise the possibility that innate receptor systems, other than those involved in sensing microbes and danger, sense allogeneic non-self on transplanted tissues and cause APC activation. Here, we will summarize evidence that monocytes and macrophages distinguish between self and allogeneic non-self and review the mechanisms and functional consequences of this form of innate 
allorecognition. We also touch on the allospecific memory in these innate immune cells and discuss the translation of the findings into clinical situations.

\section{EVIDENCE FOR INNATE ALLORECOGNITION}

An early study by Zecher et al. demonstrated that RAG-/mice, which lack $\mathrm{T}$ and $\mathrm{B}$ cells, mount a DTH-like response to allogeneic but not syngeneic $R A G-/$ - splenocytes (16). In the same study, it was established that the response is mediated by host monocytes, not NK cells, and is elicited by non-MHC disparities between donor and recipient. A subsequent publication by Liu et al. independently reported that macrophages in alloimmunized hosts engage in allorecognition, acquiring with the help of CD4+ $\mathrm{T}$ cells the ability to kill allogeneic cells (17). CD4+ T cell help to macrophages was mediated by CD40 such that the same macrophage allocytotoxic response could be elicited in lymphocyte-deficient mice injected with an anti-CD40 agonistic antibody at the time of alloimmunization.

Prompted by these observations, Oberbarnscheidt et al. studied the innate response of $R A G-/-\gamma c-/-$ mice (which lack $\mathrm{T}, \mathrm{B}, \mathrm{NK}$, as well as all other innate lymphoid cells) to heart, kidney, and bone marrow plug grafts (18). They found that allografts elicit an innate response distinct from syngeneic grafts. Allografts were persistently infiltrated with host-derived mature (MHC-IIhiCD80hi), IL-12+ monocyte-derived DCs (mo-DCs), even several weeks after transplantation, while syngeneic grafts harbored five-fold less mo-DCs, which were transient (present only during the 1st week), less mature, and IL-12neg. Similar differences were observed between allogeneic and syngeneic grafts transplanted to wild-type (WT) recipients and analyzed within 1 day after transplantation (18). Consistent with their IL-12 phenotype, mo-DCs from allografts but not those from syngeneic grafts drove a canonical Th1 $(\mathrm{IFN} \gamma+)$ response in vitro and in vivo. As in the previous study (16), the innate alloresponse was not dependent on MHC disparities between donor and recipient, or on lymphoid cells in either donor or recipient. Instead, a mismatch in the non-MHC was necessary. Chow et al. made similar observations by injecting allogeneic cells intravenously, to avoid inflammatory reactions, into $R A G-/-\gamma \mathrm{c}-/-$ mice (19). Therefore, monocytes and macrophages are activated by allogeneic stimuli to become mature DCs that drive the Th1 response and to acquire allocytotoxic functions, respectively.

\section{MECHANISM OF INNATE ALLORECOGNITION: RECOGNITION OF NON-MHC ALLODETERMINANTS}

A genetic mapping study was undertaken to identify nonMHC allodeterminants that trigger the innate alloresponse (20). The study was based on the observation that allografts from NOD donors elicit a strong monocyte response in B6. RAG$/-\gamma c-/$ - recipients, while grafts from NOR mice, which share $\sim 88 \%$ of their genome (including the MHC) with NOD, do not (20). Using NOD.NOR congenics, Dai et al. mapped the difference to the gene that encodes $\operatorname{SIRP} \alpha$ (signal regulatory protein alpha), a polymorphic IgSF (immunoglobulin super family) protein expressed on neurons and myeloid cells but also present or induced on myocytes, epithelial cells, and endothelial cells (21). They showed that SIRP $\alpha$ triggers monocyte activation via CD47 and that amino acid polymorphisms in SIRP $\alpha$ determine the strength of the innate alloresponse by modulating binding to CD47 (20). The greater binding to its ligand $\mathrm{CD} 47$ by NOD variant of $\operatorname{SIRP} \alpha$ than other mouse strains of SIRP $\alpha$ was also studied by other groups $(22,23)$. The allorecognition model (Figure 1) that emerged is that nonself SIRP $\alpha$ on donor cells causes host monocyte activation by disturbing the balance between activating and inhibitory signals mediated by $\mathrm{CD} 47$ and $\operatorname{SIRP} \alpha$, respectively. Under steady-state conditions, or upon transplanting a syngeneic graft, bidirectional interactions between CD47 and self-SIRP $\alpha$ are of equal affinity and thus prevent monocyte activation. In contrast, transplanting an allograft expressing a mismatched (non-self) SIRP $\alpha$ variant upsets the balance and causes monocyte differentiation to DC (20, 24). This model echoes NK cell allorecognition (25). At the same time, it does not exclude the possibility that other polymorphic ligands/receptors could still participate in finetuning the innate alloresponse.

\section{ALLOSPECIFIC MEMORY IN INNATE IMMUNE CELLS: RECOGNITION OF MHC-I MOLECULES}

Immunological memory - the ability of immune cells to respond rapidly and provide enhanced protection of the host against previously encountered antigen-is a critical driver of transplant rejection and outcomes (26-28). Although originally confined to $\mathrm{T} \& \mathrm{~B}$ lymphocytes, the memory concept has been expanded by discoveries that innate lymphoid and myeloid cells (NK cells and macrophages) (29-35), DCs (36), as well as nonimmune cells (epithelial stem cells) (37) acquire memory to prior microbial, phagocytosis of apoptotic cells, or allogeneic exposures. As shown in Table 1, immunological memory is not a one-size-fits-all phenomenon but falls on a spectrum of varying biological mechanisms, ranging from epigenetic reprogramming in epithelial stem cells, macrophages, and DCs to clonal expansion and differentiation (with or without gene rearrangement) in NK cells and lymphocytes (36-42). Irrespective of mechanism, all memory enhances protection of the host. Epithelial stem cell memory hastens wound healing, macrophage or DC memory protects against pathogens, and lymphoid cell memory accelerates rejection of microbial and allogeneic non-self $(31,33-37,43,44)$. The lasting state of enhanced innate immunity, innate memory, had been termed "trained immunity" and usually confined to unspecific immunological memory in innate immune cells or does not have to be specific (45-49). Recent studies also revealed extensive changes in cellular metabolism during trained macrophage immunity, such as a switch from oxidative phosphorylation toward the preferential use of aerobic glycolysis through an Akt/mTOR/HIF-1 $\alpha$-dependent pathway induced by C. albicans 


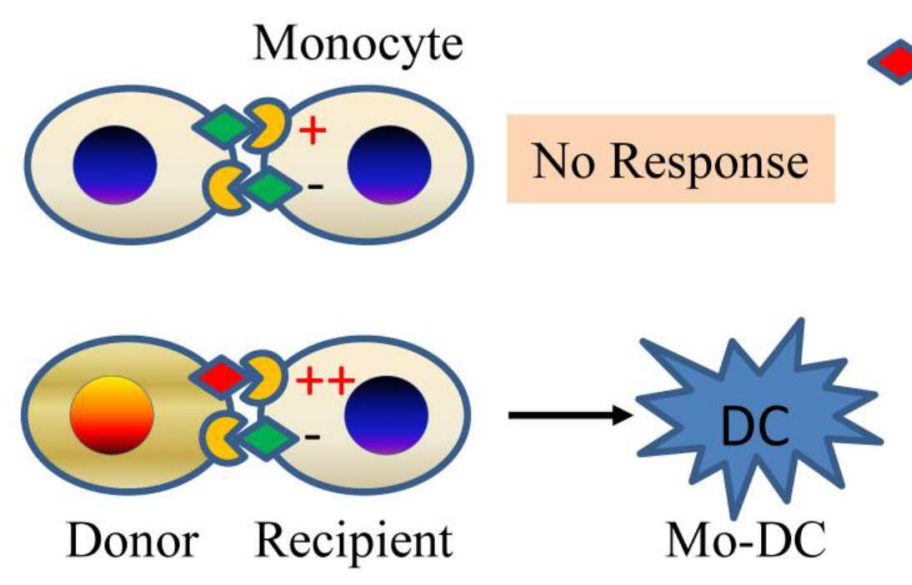

FIGURE 1 | Innate allorecognition model. SIRP $\alpha$ mismatch between donor and recipient (bottom panel) causes imbalance between stimulatory and inhibitory signals in monocytes due to differential affinity of SIRP $\alpha$ to CD47. The mismatch generates mature DCs. If monocytes encounter self (top panel), then no response ensues. Mo-DC, monocyte-derived dendritic cell.

and $\beta$-glutan (47). Strategies to regulate trained immunity had shown promise to achieve therapeutic benefits in a range of immune-related diseases (50).

In a series of experiments recently completed by our groups (51), we established that monocytes and macrophages mount an anamnestic memory response to previously encountered allogeneic donor cells but not to third-party cells. This donor specific feature was different from previous concept of "trained immunity," suggesting it is similar to the well-characterized concept of antigen-specific immunological memory in adaptive immune cells (26-28). Memory arose independently of lymphoid cells in either the donor or recipient, underscoring its innate nature. It lasted between 4 and 7 weeks after immunization, which is significantly longer than the average lifespan of a monocyte ( $\sim 3$ days) $(52,53)$. Further, we established that memory specificity was to donor MHC-I antigens that were recognized by paired immunoglobulin-like receptor A (PIR-A) molecules expressed on monocytes and macrophages. PIR-A-/- mice or mice treated with PIR-A-blocking agents failed to mount monocyte or macrophage memory. Mouse PIRs are IgSF orthologs of human leukocyte immunoglobulin-like receptors (LILRs) (54). Six linked PIR-A and one PIR-B gene have been identified (55-57). PIR-B contains an ITIM motif and is inhibitory. It binds a wide spectrum of MHC-I molecules (58). PIR-As do not contain ITIM motifs and are stimulatory through association with the Fc receptor common $\gamma(\mathrm{FcR} \gamma \mathrm{c})$ chain, also required for their surface expression $(54,59)$. PIR$A$ and PIR-B ectodomains share $>92 \%$ identity, suggesting that PIR-As also bind MHC-I (58). In fact, PIR-A diversity leads to differential binding of individual PIR-A molecules to distinct MHC-I molecules.

As to the mechanisms by which monocytes acquire allospecific memory, the PIR molecules were preferentially expressed on Ly6Chi monocytes, which significantly expanded after allogeneic antigen exposure. Specific memory independent of lymphoid cells can be transferred to an unimmunized recipient by transferring sorted Ly6Chi monocytes expanded from an immunized recipient, suggesting that clonal expansion of monocytes that express the particular PIR-A molecule that recognizes the particular MHC-I molecule in the immunogen underlies memory (51). This resembles the mechanism established in the case of allospecific NK cell memory (34). We also observed that initial activation of monocytes via the $\mathrm{SIRP} \alpha-\mathrm{CD} 47$ pathway, which plays an important role in the primary innate allorecognition response (20), is necessary for priming cells toward the memory path (51) (Figure 2).

\section{ROLE OF INNATE ALLORECOGNITION IN REJECTION}

Evidence that innate allorecognition described above plays an important role in rejection derives from three lines of investigation. In the first (18), OVA-specific OT-II T cells transferred to B6. RAG-/- hosts did not reject B6.OVA grafts but rejected (BALB/c x B6)F1.OVA grafts despite similar expression of the antigen, ovalbumin (OVA), recognized by the $\mathrm{T}$ cells. Only F1.OVA grafts induced mature mo-DCs and significant proliferation and IFN $\gamma$ production by OT-II cells, underscoring the importance of monocyte recognition of allogeneic nonself in F1 donors in driving the $\mathrm{T}$ cell response. Moreover, short-term mo-DC depletion using the CD11b-DTR transgenic system completely abrogated histological acute rejection at 7 days in lymphocyte-replete mice (18). In contrast, eliminating neutrophils (also CD11b+) with a neutrophil-specific mAb did not affect rejection (18).

In the second study (60), the origin and function of DCs in heart and kidney allografts after transplantation to WT recipients were investigated. It was established that donorderived DCs were quickly replaced by DCs derived from recipient monocytes and that they closely resembled mo-DCs generated by innate allorecognition. They were mature, IL-12+, and induced 
TABLE 1 | Spectrum of immunological memory.

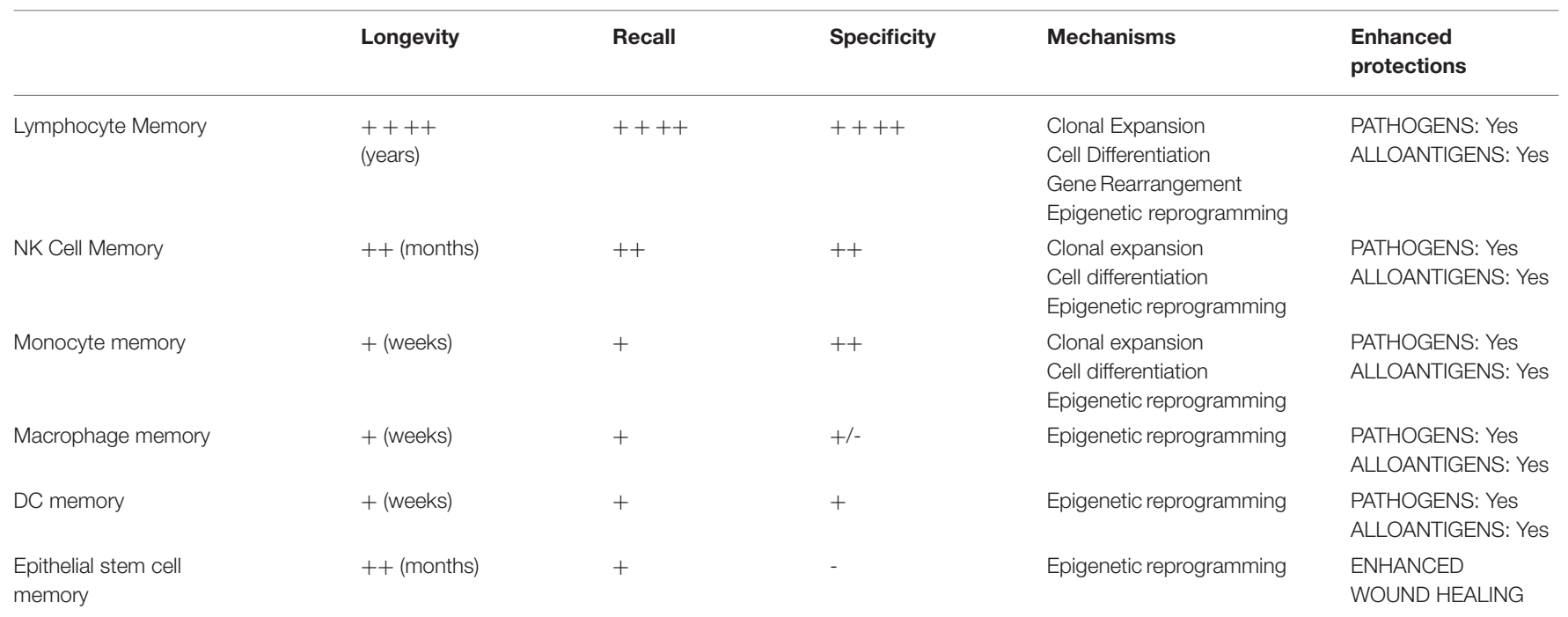

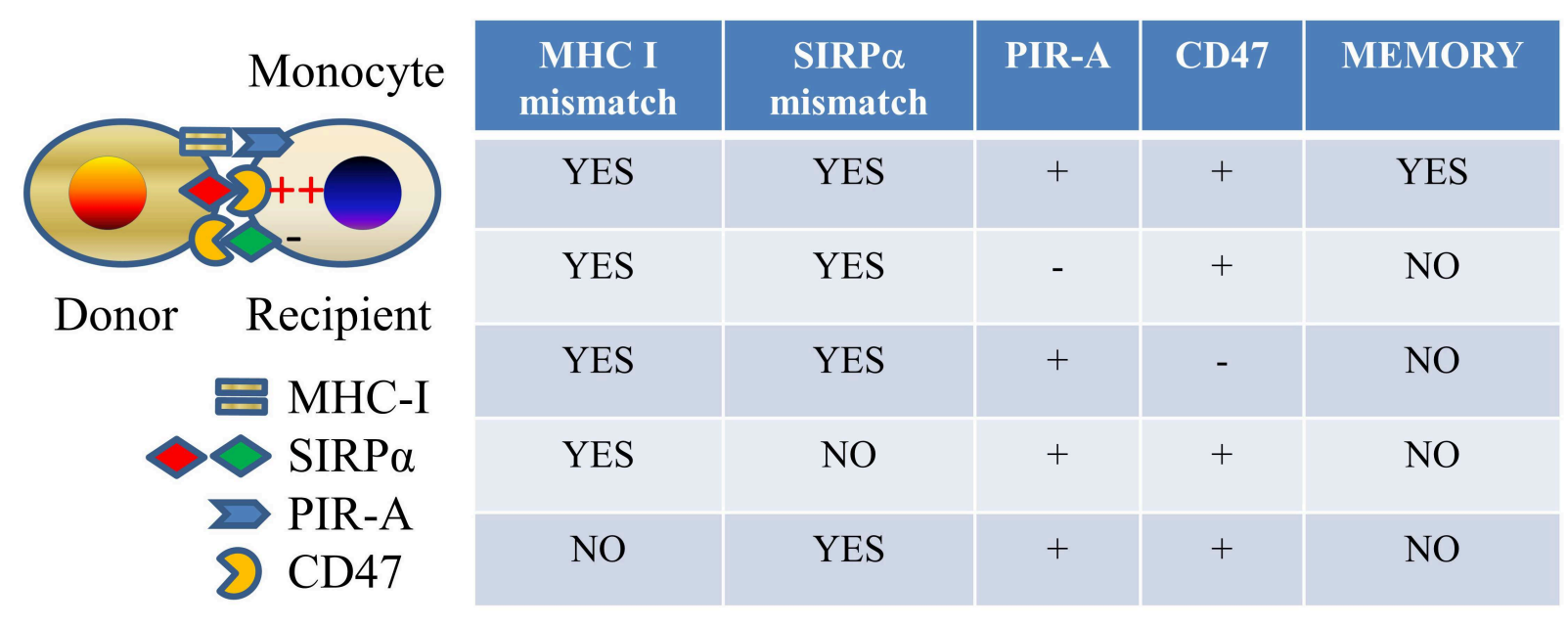

FIGURE 2 | Allospecific innate memory mechanism. Mismatches of both MHC I and SIRP $\alpha$ between donor and recipient and expressions of both PIR-A and CD47 molecules on recipient monocytes are required for establishing monocyte allospecific memory.

Th1 differentiation. In the graft, they made stable, cognate interactions with effector $\mathrm{T}$ cells and increased $\mathrm{T}$ cell proliferation and survival. DC depletion starting on day 5 delayed heart allograft rejection by $>30$ days in WT recipients (60) and completely prevented rejection in mice that lacked $2^{\circ}$ lymphoid organs (splenectomized LT $\beta$ R-/- mice) after transfer of effector T cells. Therefore, host mo-DCs that persistently infiltrate allografts sustain T cell-mediated rejection locally.

In the third set of experiments $(51,61)$, innate allorecognition and memory molecular pathways were interrupted. We observed that mouse renal allografts transplanted to recipients that lack either CD47 or PIR-A develop significantly less manifestations of chronic rejection. Similarly, blocking the PIR-A pathway led to long-term heart allograft survival with minimal pathology in recipients simultaneously treated with co-stimulation blockade (CTL4Ig). Acute rejection, however, was either not delayed or only modestly improved if either CD47 or PIR-A was absent. Therefore, the major influence of the SIRP $\alpha-C D 47$ and MHC-I-PIR-A pathways is on chronic allograft rejection and on preventing allograft acceptance. In contrast, rejection was accelerated in the absence of PIR-B signaling in the recipient.

\section{CLINICAL TRANSLATION IN TRANSPLANTATION}

In humans, interactions through similar signaling pathways mediated by $\operatorname{SIRP} \alpha$ and PIRs' homolog LILRs engaging with CD47 and MHC-I molecules, respectively, also exist $(62,63)$. By $\mathrm{x}$-ray crystallography, Hatherley $\mathrm{D}$ et al. showed that the polymorphism in human $\operatorname{SIRP} \alpha$ did not affect binding to its ligand CD47 (64). This suggested the possibility, although 
requiring further exploration, that human $\operatorname{SIRP} \alpha$ differed in binding features from mouse $\operatorname{SIRP} \alpha$, whose binding affinity to its ligand CD47 was recognized to be dependent on its polymorphic IgV domain $(20,24)$. Our preliminary data also validated that the amino-terminal ligand binding domain of human SIRP $\alpha$ is highly polymorphic (65). Human LILRs family comprises a set of PIRs (A and B) expressed on myeloid innate immune cells. Similar to PIRs in mice, LILR-Bs contain ITIM motifs and are inhibitory while LILR-As do not contain ITIM motifs but contain ITAM motifs and are stimulatory. Six LILR-As and five LILR-Bs have been identified. Both LILR-As and LILR-Bs bind a wide spectrum of MHC-I molecules $(63,66)$. Human $\mathrm{SIRP} \alpha-\mathrm{CD} 47$ interaction has been reported to be implicated in the phagocytosis of red blood cells and leukemia cells by macrophages in vivo or in vitro $(62,67)$. There are data suggesting a link between LILR polymorphism and control of HIV infection and autoimmunity in humans $(63,66)$. However, published human studies on the roles of SIRP $\alpha$ and LILRs in transplantation are not available yet. The similarities in these two pathways (SIRP $\alpha-C D 47$ and MHC-I-PIR-A/LILR-A) between human and mice should trigger investigations into the roles of these pathways in clinical transplantation.

\section{CONCLUDING REMARKS}

We have presented evidence that the innate immune cells, namely, monocytes and macrophages, respond to allogeneic

\section{REFERENCES}

1. Janeway CA, Jr. Approaching the asymptote? Evolution revolution in immunology. Cold Spring Harb Symp Quant Biol. (1989) 54:1-13. doi: 10.1101/SQB.1989.054.01.003

2. Iwasaki A Medzhitov R. Regulation of adaptive immunity by the innate immune system. Science. (2010) 327:291-5. doi: 10.1126/science.1183021

3. Goldstein DR, Tesar BM, Akira S, Lakkis FG. Critical role of the toll-like receptor signal adaptor protein MyD88 in acute allograft rejection. J Clin Invest. (2003) 111:1571-8. doi: 10.1172/JCI200317573

4. Tesar BM, Zhang J, Li Q, Goldstein DR. TH1 immune responses to fully MHC mismatched allografts are diminished in the absence of MyD88, a toll-like receptor signal adaptor protein. Am J Transplant. (2004) 4:142939. doi: 10.1111/j.1600-6143.2004.00544.x

5. Hutton MJ, Westwell-Roper C, Soukhatcheva G, Plesner A, Dutz JP, Verchere $\mathrm{CB}$. Islet allograft rejection is independent of toll-like receptor signaling in mice. Transplantation. (2009) 88:1075-80. doi: 10.1097/TP.0b013e3181bd3fe2

6. McKay D, Shigeoka A, Rubinstein M, Surh C, Sprent J. Simultaneous deletion of MyD88 and trif delays major histocompatibility and minor antigen mismatch allograft rejection. Eur J Immunol. (2006) 36:19942002. doi: 10.1002/eji.200636249

7. Oberbarnscheidt MH, Obhrai JS, Williams AL, Rothstein DM, Shlomchik WD, Chalasani G, et al. Type I interferons are not critical for skin allograft rejection or the generation of donor-specific CD8+ memory T cells. Am J Transplant. (2010) 10:162-7. doi: 10.1111/j.1600-6143.2009.02871.x

8. Li H, Matte-Martone C, Tan HS, Venkatesan S, McNiff J, Demetris AJ, et al. Graft-versus-host disease is independent of innate signaling pathways triggered by pathogens in host hematopoietic cells. J Immunol. (2011) 186:230-41. doi: 10.4049/jimmunol.1002965

9. Matzinger P. Tolerance, danger, and the extended family. Annu Rev Immunol. (1994) 12:991-1045. doi: 10.1146/annurev.iy.12.040194.0 05015 non-self independently of T, B, and NK cells. This form of allorecognition initiates or sustains the responses of recipient $\mathrm{T}$ cells to allografts by inducing the maturation of APCs. It also provides phagocytic cells with the means to kill allogeneic targets without inflicting damage on self-tissues. One mechanism of innate allorecognition is the differential binding of CD47 on monocytes to polymorphic SIRP $\alpha$ on donor cells. We also summarized data showing that monocytes and macrophages acquire memory specific to allogeneic MHC-I molecules that is dependent on MHC-I sensing by polymorphic PIR-A molecules. Blocking $\operatorname{SIRP} \alpha-$ CD47 or MHC-I-PIR-A interaction shows promise in preventing chronic rejection or promoting allograft acceptance. Future studies are expected to establish translation of these findings into clinical transplantation.

\section{AUTHOR CONTRIBUTIONS}

DZ and FL wrote manuscript. KA-D and HD contributed data and edited manuscript. MO and XL edited manuscript.

\section{FUNDING}

This work was supported by NIH grants AI099465 (FL), AI145881 (MO), and AI080779 (XL) and the Frank \& Athsena Sarris Chair in Transplantation Biology (FL).
10. Gallucci S, Lolkema M, Matzinger P. Natural adjuvants: endogenous activators of dendritic cells. Nat Med. (1999) 5:1249-55. doi: 10.1038/15200

11. Bingaman AW, Ha J, Waitze SY, Durham MM, Cho HR, Tucker-Burden C, et al. Vigorous allograft rejection in the absence of danger. J Immunol. (2000) 164:3065-71. doi: 10.4049/jimmunol.164.6.3065

12. Anderson CC, Carroll JM, Gallucci S, Ridge JP, Cheever AW, Matzinger P. Testing time-, ignorance-, and danger-based models of tolerance. J Immunol. (2001) 166:3663-71. doi: 10.4049/jimmunol.166.6.3663

13. Chan WF, Perez-Diez A, Razavy H, Anderson CC. The ability of natural tolerance to be applied to allogeneic tissue: determinants and limits. Biol Direct. (2007) 2:10. doi: 10.1186/1745-6150-2-10

14. Zecher D, Li Q, Oberbarnscheidt MH, Demetris AJ, Shlomchik WD, Rothstein $\mathrm{DM}$, et al. NK cells delay allograft rejection in lymphopenic hosts by downregulating the homeostatic proliferation of CD8+ T cells. J Immunol. (2010) 184:6649-57. doi: 10.4049/jimmunol.0903729

15. Chalasani G, Li Q, Konieczny BT, Smith-Diggs L, Wrobel B, Dai Z, et al. The allograft defines the type of rejection (acute versus chronic) in the face of an established effector immune response. J Immunol. (2004) 172:781320. doi: 10.4049/jimmunol.172.12.7813

16. Zecher D, van Rooijen N, Rothstein D, Shlomchik W, Lakkis F. An innate response to allogeneic nonself mediated by monocytes. J Immunol. (2009) 183:7810-6. doi: 10.4049/jimmunol.0902194

17. Liu W, Xiao X, Demirci G, Madsen J, Li XC. Innate NK cells and macrophages recognize and reject allogeneic nonself in vivo via different mechanisms. $J$ Immunol. (2012) 188:2703-11. doi: 10.4049/jimmunol.1102997

18. Oberbarnscheidt MH, Zeng Q, Li Q, Dai H, Williams AL, Shlomchik WD, et al. Non-self recognition by monocytes initiates allograft rejection. J Clin Invest. (2014) 124:3579-89. doi: 10.1172/JCI74370

19. Chow KV, Delconte RB, Huntington ND, Tarlinton DM, Sutherland $\mathrm{RM}$, Zhan $\mathrm{Y}$, et al. Innate allorecognition results in rapid accumulation of monocyte-derived dendritic cells. J Immunol. (2016) 197:2000-8. doi: 10.4049/jimmunol.1600181 
20. Dai H, Friday AJ, Abou-Daya KI, Williams AL, Mortin-Toth S, Nicotra ML, et al. Donor SIRPa polymorphism modulates the innate immune response to allogeneic grafts. Sci Immunol. (2017) 2:eaam6202. doi: 10.1126/sciimmunol.aam6202

21. Barclay AN, Van den Berg TK. The interaction between signal regulatory protein alpha (SIRPalpha) and CD47: structure, function, and therapeutic target. Annu Rev Immunol. (2014) 32:25-50. doi: 10.1146/annurev-immunol-032713-120142

22. Yamauchi T, Takenaka K, Urata S, Shima T, Kikushige Y, Tokuyama T, et al. Polymorphic sirpa is the genetic determinant for NOD-based mouse lines to achieve efficient human cell engraftment. Blood. (2013) 121:131625. doi: 10.1182/blood-2012-06-440354

23. Wong AS, Mortin-Toth S, Sung M, Canty AJ, Gulban O, Greaves DR, et al. Polymorphism in the innate immune receptor SIRPalpha controls CD47 binding and autoimmunity in the nonobese diabetic mouse. I Immunol. (2014) 193:4833-44. doi: 10.4049/jimmunol.1401984

24. Menon MC, Heeger PS. Donor SIRP-alpha polymorphisms: widening the innate-to-adaptive continuum in allograft rejection. Kidney Int. (2017) 92:1305-8. doi: 10.1016/j.kint.2017.10.006

25. Legrand N, Huntington ND, Nagasawa M, Bakker AQ, Schotte R, StrickMarchand $\mathrm{H}$, et al. Functional CD47/signal regulatory protein alpha [SIRP(alpha)] interaction is required for optimal human T- and natural killer(NK) cell homeostasis in vivo. Proc Natl Acad Sci USA. (2011) 108:132249. doi: 10.1073/pnas.1101398108

26. Espinosa JR, Samy KP, Kirk AD. Memory $\mathrm{T}$ cells in organ transplantation: progress and challenges. Nat Rev Nephrol. (2016) 12:339-47. doi: 10.1038/nrneph.2016.9

27. Ford ML, Larsen CP. Overcoming the memory barrier in tolerance induction: molecular mimicry and functional heterogeneity among pathogenspecific T-cell populations. Curr Opin Organ Transplant. (2010) 15:40510. doi: 10.1097/MOT.0b013e32833b7916

28. Macedo C. Orkis EA, Popescu I, Elinoff BD, Zeevi A, Shapiro $\mathrm{R}$, et al. Contribution of naïve and memory T-cell populations to the human alloimmune response. Am J Transplant. (2009) 9:2057-66. doi: 10.1111/j.1600-6143.2009.02742.x

29. O'Leary JG, Goodarzi M, Drayton DL, von Andrian UH. T cell- and B cell-independent adaptive immunity mediated by natural killer cells. Nat Immunol. (2006) 7:507-16. doi: 10.1038/ni1332

30. Paust S, Gill HS, Wang BZ, Flynn MP, Moseman EA, Senman B, et al. Critical role for the chemokine receptor CXCR6 in NK cell-mediated antigenspecific memory of haptens and viruses. Nat Immunol. (2010) 11:112735. doi: 10.1038/ni.1953

31. Sun JC, Beilke JN, Lanier LL. Adaptive immune features of natural killer cells. Nature. (2009) 457:557-61. doi: 10.1038/nature07665

32. Cooper MA. Elliott JM, Keyel PA, Yang L, Carrero JA, Yokoyama WM. Cytokine-induced memory-like natural killer cells. Proc Natl Acad Sci USA. (2009) 106:1915-9. doi: 10.1073/pnas.0813192106

33. Quintin J. Saeed S, Martens JH, Giamarellos-Bourboulis EJ, Ifrim DC, Logie $\mathrm{C}$, et al. Candida albicans infection affords protection against reinfection via functional reprogramming of monocytes. Cell Host Microbe. (2012) 12:22332. doi: 10.1016/j.chom.2012.06.006

34. Nabekura T and Lanier LL. Antigen-specific expansion and differentiation of natural killer cells by alloantigen stimulation. J Exp Med. (2014) 211:245565. doi: 10.1084/jem.20140798

35. Weavers H, Evans IR, Martin P, Wood W. Corpse engulfment generates a molecular memory that primes the macrophage inflammatory response. Cell. (2016) 165:1658-71. doi: 10.1016/j.cell.2016.04.049

36. Hole CR, Wager CML, Castro-Lopez N, Campuzano A, Cai H, Wozniak KL, et al. Induction of memory-like dendritic cell responses in vivo. Nat Commun. (2019) 10:2955. doi: 10.1038/s41467-01910486-5

37. Naik S, Larsen SB, Gomez NC, Alaverdyan K, Sendoel A, Yuan S, et al. Inflammatory memory sensitizes skin epithelial stem cells to tissue damage. Nature. (2017) 550:475-80. doi: 10.1038/nature24271

38. Saeed S, Quintin J, Kerstens HH, Rao NA, Aghajanirefah A, Matarese $\mathrm{F}$, et al. Epigenetic programming of monocyte-to-macrophage differentiation and trained innate immunity. Science. (2014) 345:1251086. doi: $10.1126 /$ science. 1251086
39. O'Sullivan TE, Sun JC, Lanier LL. Natural killer cell memory. Immunity. (2015) 43:634-45. doi: 10.1016/j.immuni.2015.09.013

40. Cerwenka A, Lanier LL. Natural killer cell memory in infection, inflammation and cancer. Nat Rev Immunol. (2016) 16:112-23. doi: 10.1038/nri.2015.9

41. Lee J. Zhang T, Hwang I, Kim A, Nitschke L, Kim M, et al. Epigenetic modification and antibody-dependent expansion of memory-like NK cells in human cytomegalovirus-infected individuals. Immunity. (2015) 42:43142. doi: 10.1016/j.immuni.2015.02.013

42. Luetke-Eversloh M, Hammer Q, Durek P, Nordstrom K, Gasparoni G, Pink $M$, et al. Human cytomegalovirus drives epigenetic imprinting of the IFNG locus in NKG2Chi natural killer cells. PLoS Pathog. (2014) 10:e1004441. doi: 10.1371/journal.ppat.1004441

43. Kleinnijenhuis J, Quintin J, Preijers F, Joosten LA, Ifrim DC, Saeed S, et al. Bacille calmette-guerin induces NOD2-dependent nonspecific protection from reinfection via epigenetic reprogramming of monocytes. Proc Natl Acad Sci USA. (2012) 109:17537-42. doi: 10.1073/pnas.1202870109

44. Ahmed $\mathrm{R}$ Gray $\mathrm{D}$. Immunological memory and protective immunity: understanding their relation. Science. (1996) 272:5460. doi: $10.1126 /$ science. 272.5258 .54

45. Netea MG, Quintin J, van der Meer JW. Trained immunity: a memory for innate host defense. Cell Host Microbe. (2011) 9:355-61. doi: 10.1016/j.chom.2011.04.006

46. Netea MG. Training innate immunity: the changing concept of immunological memory in innate host defence. Eur J Clin Invest. (2013) 43:881-4. doi: $10.1111 /$ eci.12132

47. Netea MG, Joosten LA, Latz E, Mills KH, Natoli G, Stunnenberg HG, et al. Trained immunity: a program of innate immune memory in health and disease. Science. (2016) 352:aaf1098. doi: 10.1126/science. aaf1098

48. Gardiner CM Mills KH. The cells that mediate innate immune memory and their functional significance in inflammatory and infectious diseases. Semin Immunol. (2016) 28:343-50. doi: 10.1016/j.smim.2016.03.001

49. Pradeu T, Du Pasquier L. Immunological memory: what's in a name? Immunol Rev. (2018) 283:7-20. doi: 10.1111/imr.12652

50. Mulder WJM, Ochando J, Joosten LAB, Fayad ZA, Netea MG. Therapeutic targeting of trained immunity. Nat Rev Drug Discov. (2019) 18:55366. doi: 10.1038/s41573-019-0025-4

51. Dai H, Lan P, Zhao D, Abou-Daya K, Liu W, Chen W, et al. Paired immunoglobulin-like receptors mediate myeloid cell memory to non-self MHC molecules. Under Rev. (2020). doi: 10.1126/science.aax4040. [Epub ahead of print].

52. Patel AA, Zhang Y, Fullerton JN, Boelen L, Rongvaux A, Maini AA, et al. The fate and lifespan of human monocyte subsets in steady state and systemic inflammation. J Exp Med. (2017) 214:1913-23. doi: 10.1084/jem.201 70355

53. Yona S, Kim KW, Wolf Y, Mildner A, Varol D, Breker M, et al. Fate mapping reveals origins and dynamics of monocytes and tissue macrophages under homeostasis. Immunity. (2013) 38:79-91. doi: 10.1016/j.immuni.2012.12.001

54. Kubagawa H, Chen CC, Ho LH, Shimada TS, Gartland L, Mashburn $\mathrm{C}$, et al. Biochemical nature and cellular distribution of the paired immunoglobulin-like receptors, PIR-A and PIR-B. J Exp Med. (1999) 189:30918. doi: 10.1084/jem.189.2.309

55. Kubagawa H, Burrows PD, Cooper MD. A novel pair of immunoglobulinlike receptors expressed by B cells and myeloid cells. Proc Natl Acad Sci USA. (1997) 94:5261-6. doi: 10.1073/pnas.94.10.5261

56. Takai T. Paired immunoglobulin-like receptors and their MHC class I recognition. Immunology. (2005) 115:43340. doi: 10.1111/j.1365-2567.2005.02177.x

57. Tun T, Kubagawa Y, Dennis G, Burrows PD, Cooper MD, Kubagawa H Genomic structure of mouse PIR-A6, an activating member of the paired immunoglobulin-like receptor gene family. Tissue Antigens. (2003) 61:22030. doi: 10.1034/j.1399-0039.2003.00042.x

58. Nakamura A, Kobayashi E, Takai T. Exacerbated graft-versus-host disease in Pirb-/- mice. Nat Immunol. (2004) 5:623-9. doi: 10.1038/ni1074

59. Maeda A, Kurosaki M, Kurosaki T. Paired immunoglobulin-like receptor (PIR)-A is involved in activating mast cells through its association with fc receptor gamma chain. J Exp Med. (1998) 188:991-5. doi: 10.1084/jem.188.5.991 
60. Zhuang Q, Liu Q, Divito SJ, Zeng Q, Yatim KM, Hughes AD, et al. Graftinfiltrating host dendritic cells play a key role in organ transplant rejection. Nat Commun. (2016) 7:12623. doi: 10.1038/ncomms12623

61. Zhao D, Dai H, Abou-Daya K, Williams A, Oberbarnscheidt M, Li X, et al. Role of innate allorecognition pathways in mouse renal allograft rejection [abstract]. Am J Transplant. (2019) 19(Suppl 3):289-92. doi: 10.1111/ajt.14436

62. Murata Y, Kotani T, Ohnishi H, Matozaki T. The CD47-SIRPalpha signalling system: its physiological roles and therapeutic application. J Biochem. (2014) 155:335-44. doi: 10.1093/jb/mvu017

63. Hudson LE Allen RL. Leukocyte Ig-like receptors - a model for MHC class $\mathrm{i}$ disease associations. Front Immunol. (2016) 7:281. doi: 10.3389/fimmu.2016.00281

64. Hatherley D, Lea SM, Johnson S, Barclay AN. Polymorphisms in the human inhibitory signal-regulatory protein alpha do not affect binding to its ligand CD47. J Biol Chem. (2014) 289:10024-8. doi: 10.1074/jbc.M114.550558

65. Friday A, Dai H, Williams A, Oberbarnscheidt M, Danska J, Lakkis F. Identification of human SIRPa diversity that could regulate innate allorecognition [abstract]. Am J Transplant. (2017) 17(Suppl 3):307. doi: 10.1111/ajt.14304
66. van der Touw W, Chen HM, Pan PY, Chen SH. LILRB receptor-mediated regulation of myeloid cell maturation and function. Cancer Immunol Immunother. (2017) 66:1079-87. doi: 10.1007/s00262-017-2023-X

67. Lin Y, Yan XQ, Yang F, Yang XW, Jiang X, Zhao XC, et al. Soluble extracellular domains of human SIRPalpha and CD47 expressed in escherichia coli enhances the phagocytosis of leukemia cells by macrophages in vitro. Protein Expr Purif. (2012) 85:109-16. doi: 10.1016/j.pep.2012.07.002

Conflict of Interest: The authors declare that the research was conducted in the absence of any commercial or financial relationships that could be construed as a potential conflict of interest.

Copyright (C) 2020 Zhao, Abou-Daya, Dai, Oberbarnscheidt, Li and Lakkis. This is an open-access article distributed under the terms of the Creative Commons Attribution License (CC BY). The use, distribution or reproduction in other forums is permitted, provided the original author(s) and the copyright owner(s) are credited and that the original publication in this journal is cited, in accordance with accepted academic practice. No use, distribution or reproduction is permitted which does not comply with these terms. 